\title{
Causas de mortalidade em leitões em granja comercial do médio-norte de Mato Grosso*
}

\section{Causes of losses in piglets in commercial farm at the middle north of Mato Grosso State}

\author{
João Garcia Caramori Júnior,, Gilson Mendes Araújo, ${ }^{* * *}$ Flávio Medeiros Vieites, ${ }^{* * *}$ Joadil G. Abreu, ${ }^{* * * *}$ \\ Vivian C. Cochove, ${ }^{\star * \star * \star *}$ Gustavo S. Silva ${ }^{\star \star \star * \star \star *}$
}

\begin{abstract}
Resumo
O objetivo deste trabalho foi avaliar e classificar as principais causas de morte de leitões com até seis dias de idade, em um sistema intensivo de suínos confinados (SISCO), localizado na região médio-norte do estado de Mato Grosso durante o ano de 2006. Observaram-se 48.416 leitões provenientes de 2.054 matrizes. Verificou-se taxa de mortalidade de $7,43 \%$ do total de nascidos vivos. As causas mais frequentes de mortalidade, em relação ao total de nascidos vivos, foram esmagamento $(24,14 \%)$, debilitação $(8,01 \%)$, síndrome diarreica $(6,0 \%)$, defeitos genéticos $(2,41 \%)$ e outras causas sem diagnóstico confirmado durante a necrópsia (15,20\%). A taxa de natimortalidade em relação ao total de nascidos foi de $5,59 \%$. Com relação à sazonalidade das mortes, observou-se maior índice de mortalidade por síndrome diarreica durante a primavera, que coincide com os meses mais quentes do ano, não observando tendência para morte por esmagamento em nenhuma época do ano.
\end{abstract}

Palavras-chave: diarreia, esmagamento, leitões, mortalidade.

\begin{abstract}
The objective of this research was to evaluate and to classify (by means of postmortem findings), the occurrence of the preweaning losses of piglets until the six days of age, in a intensive system of bordered pigs, at the middle north of Mato Grosso State during the year 2006. They had been observed a total of 48.416 piglets proceeding from 2.054 wombs. Was verified the tax of mortality of $7,43 \%$ of that livings piglets had been born. The most frequent causes of losses were overlaying $(24.14 \%)$, diverse causes (15.20), weakness $(8.01 \%)$, diarrhea syndrome $(6.0 \%)$ and genetic defects $(2.41 \%)$. Stillbirth rate, in relation to total born, was $5.59 \%$. In relation of periodicity deaths, it was observed a higher number of diarrhea syndrome during the spring, that coincides with the hottest months of the year, wasn't observed trends of overlaying deaths none time during the year.
\end{abstract}

Keywords: diarrhea, overlaying piglets, preweaning, recently born.

\section{Introdução}

A suinocultura, por ser uma produção de larga escala, trabalha com limites estreitos de lucros e resultados. De acordo com Lisboa (1996), a mortalidade na espécie suína pode atingir altos índices do nascimento à desmama, de $15 \%$ a $18 \%$, sendo que de $2,4 \%$ a $10 \%$ morrem durante o parto, mantendo altas taxas de mortalidade na primeira semana de vida dos leitões. No mundo, $4 \%$ a $10 \%$ dos suínos nascidos morrem durante o parto e outros $20 \%$ a $30 \%$ podem morrer antes do desmame (Abrahão et al., 2004).
O maior número de mortes ocorre entre os três e sete primeiros dias de vida. As causas desses problemas são complexas e exigem avaliações aprofundadas em cada sistema de criação, para identificá-las e tomar as medidas corretivas (Freitas, 1996). Se a mortalidade for reduzida na fase de aleitamento haverá um retorno econômico maior (Sesti e Sobestiansky, 1998).

As causas de mortalidade podem estar relacionadas com o desenho e espaço da cela-maternidade, aquecimento e manejo das fontes de calor, higiene das instalações, capaci-

\footnotetext{
* Projeto de Pesquisa financiado pela FAPEMAT.

** DSc., professor adjunto do Departamento de Produção Animal - FAMEV/UFMT, Cuiabá - MT, caramori@ufmt.br

*** Curso de mestrado em Ciência Animal, FAMEV/UFMT, Cuiabá - MT, mendes.gilson@gmail.com

**** Instituto de Ciências Exatas e Naturais - Zootecnia - UFMT, Rondonópolis - MT, professor adjunto do Departamento de Produção Animal - FAMEV/UFMT, Cuiabá - MT, fmvieites@yahoo.com.br

***** Professor adjunto do Departamento de Zootecnia e Extensão Rural , FAMEV/UFMT - joadil@@terra.com.br

****** Curso de mestrado em Ciência Animal, FAMEV/UFMT - viochove@yahoo.com.br

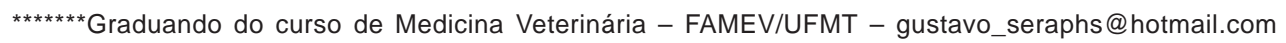


tação e dedicação de colaboradores do setor da maternidade, além dos problemas de natureza infecciosa ou não infecciosa, que podem afetar a sobrevivência dos leitões (Cuttler et al., 1999).

Durante a fase de aleitamento, os problemas que ocasionam maiores perdas econômicas nas criações de suínos são a mortalidade de leitões, a ocorrência de diarreias e o surgimento de leitões com pouco desenvolvimento (refugos) (Mores 1993).

O objetivo deste trabalho foi verificar as ocorrências e causas de perdas de leitões com até seis dias de idade através de exames de necrópsia em um sistema intensivo de suínos confinados (SISCO).

\section{Materiais e métodos}

O estudo foi desenvolvido em sistema intensivo de suínos confinados (SISCO) localizado na região médio-norte do estado de Mato Grosso durante o ano de 2006, em sistema de ciclo completo com 2.054 matrizes. Os dados zootécnicos da granja em estudo estão apresentados na Tabela 1.

Todas as instalações da granja comercial seguem os padrões técnicos recomendados para criação de suínos em clima quente: com telas e cortinas, pé direito de $3,0 \mathrm{~m}$ de altura, atendendo aos aspectos de bem-estar animal e facilidade para o manejo sanitário e produtivo. As maternidades eram subdivididas em baias individuais, contendo espaço privativo das matrizes e dos leitões, com escamoteador aquecido com lâmpada incandescente de 100 watts. Transferiram-se as matrizes para a maternidade quatro dias antes da data prevista do parto. Todos os partos foram assistidos e os eventos diários registrados em fichas na maternidade da granja. A água era fornecida de forma contínua para os leitões em bebedouros tipo chupeta com $15 \mathrm{~cm}$ de altura. Não houve fornecimento de ração nesse período para os leitões, pois a granja adota o fornecimento a partir do sétimo dia de idade.

Coletaram-se os dados durante o ano de 2006, alcançando 4.519 partos, com total de 48.416 leitões nascidos. Todas as leitegadas eram diariamente inspecionadas para verificação da cicatrização do umbigo e realização de exame clínico da atitude do leitão, para detectar alguma anormalidade clínica. Em caso de óbito, procedeu-se à necrópsia dos leitões. De acordo com o tipo e qualidade das informações obtidas neste processo, a causa da morte foi identificada, classificada e inserida em um grupo de causas, seguindo a classificação sugerida por Abrahão et al. (2004) conforme Quadro 1.
Tabela 1: Dados zootécnicos sobre a produtividade anual da granja comercial em estudo

\begin{tabular}{l|l}
\hline Características & Quantidades \\
\hline Partos & 4.519 \\
Total de leitões & \\
$\bullet \quad$ Nascidos & 48.416 \\
$\bullet \quad$ Nascidos vivos & 45.706 \\
$\bullet \quad$ Natimortos & $2.710(5,59 \%)$ \\
Mortalidade até os seis dias de vida & $3.419(7,43 \%)$ \\
Leitões desmamados & $42.479(92,93 \%)$ \\
Média de nascido por parto & 10,71 \\
Média de nascidos vivos por parto & 10,12 \\
Média de desmamados por parto & 9,4 \\
\hline
\end{tabular}

Quadro 1: Classificações diagnósticas da causa de óbito, com base nas evidências clínicas e exames necroscópicos dos leitões.

Fonte: Adaptado de Abrahão et al. (2004).

\section{Resultados e discussões}

A incidência das diferentes causas de mortes até os seis dias está representada nas Figuras 1 e 2

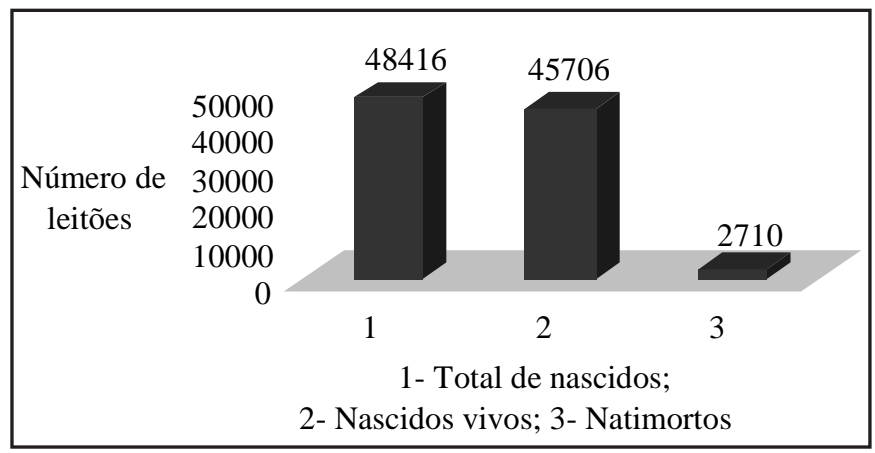

Figura 1: Nascimento de leitões em 2006

1 Natimortalidade
2 Baixo peso $(<800 \mathrm{~g})$
3 Defeito genético
4 Esmagamento
5 Diarreias
6 Outras causas

6 Outras causas 


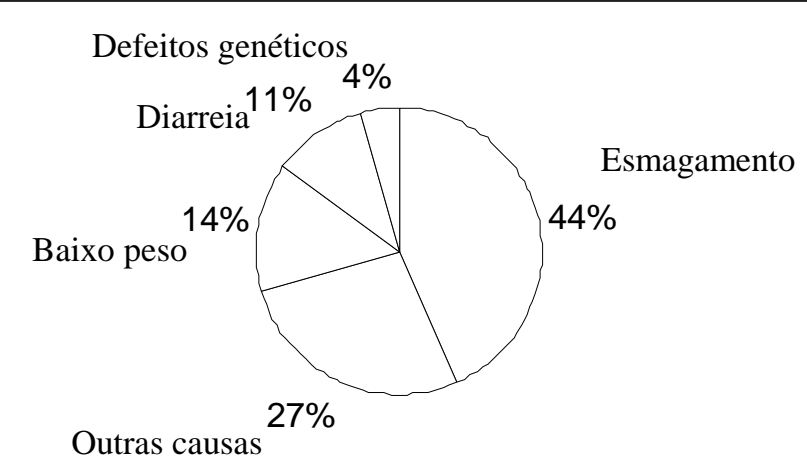

Figura 2: Causas da morte de leitões com até seis dias de idade em granjacomercial do médio-norte de Mato Grosso - MT

A taxa anual média de mortalidade na primeira semana de vida foi de $7,43 \%$. Este valor está de acordo com os índices de mortalidade relatados por Lisboa (1996), que cita mortalidade na primeira semana de vida entre $2,4 \%$ a $10,0 \%$. Abrahão et al. (2004), em pesquisa realizada no estado de São Paulo, referiram índice de mortalidade na primeira semana de vida dos leitões de 5,63\%.Os autores Sesti e Sobestiansky (1998) sugerem, como parâmetro de produtividade para os sistemas de produção de suínos modernos com alta tecnologia, taxa de mortalidade no prédesmame de, no máximo, 6\%.

A taxa anual de natimortalidade foi de 5,59\% (do total de nascidos). Abrahão et al. (2004) obtiveram resultados semelhantes (5,96\%), assim como Holanda et al. (2000) $(5,03 \%)$ com a raça Large White. A natimortalidade pode representar a quarta parte de todas as mortes registradas no intervalo parto-desmama, sendo considerada a principal causa de morte no período, com incidência de 4\% a $10 \%$ (Cuttler et al., 1999).

A morte dos leitões por esmagamento foi de $3,24 \%$ do total de nascidos vivos, seguido de baixo peso (1,06\%), síndrome diarreica $(0,79 \%)$ e defeitos genéticos $(0,31 \%)$. Abrahão et al. (2004) relataram taxa inferior para mortalidade por esmagamento $(2,61 \%)$ e taxas superiores para baixo peso $(1,45 \%)$, síndrome diarreica $(1,10 \%)$ e defeitos genéticos $(0,56 \%)$. Entretanto, os resultados demonstram que as causas de mortes de leitões na primeira semana de vida podem variar de um ano para outro, assim como a época do ano e do clima no local em estudo.

Dentro das mortes ocorridas até os seis dias de idade, as taxas foram de $43,28 \%$ para esmagamento, 27,25\% para outras causas nas identificadas pela necrópsia, 14,36\% para baixo peso (peso inferior a $800 \mathrm{~g}$ ), 10,76\% para síndrome diarreica e 4,32\% para defeitos genéticos. Verificou-se que o esmagamento é a principal causa da morte de leitões nascidos vivos, fato também observado por Abrahão et al. (2004), no estado de São Paulo, com 36,41\%, e por Vrbanac et al. (1995) na Bósnia Herzegovina, $41 \%$ do total de mortes.

Acredita-se que se houver mais esforços da mão de obra no setor de maternidade, as causas que levam ao esmagamento podem reduzir significativamente.

Em relação à sazonalidade das mortes, observou-se tendência no aumento de mortes por síndrome diarreica nos meses da primavera, provavelmente pela influência da alta temperatura ocorrida nesses meses no estado de Mato Grosso. Neste período, uma maior quantidade de água é utilizada na limpeza da maternidade, o que auxilia na troca de calor das matrizes e leitões. Altas temperaturas associadas aos índices elevados de umidade favorecem a ocorrência de diarreias. Mores et al. (1991) destacam, entre outros fatores que fazem parte do conjunto de variáveis associados à ocorrência de diarreia, a amplitude térmica maior que $6^{\circ} \mathrm{C}$ na maternidade por um período superior a dez dias. Entretanto, Abrahão et al. (2004) observaram tendência de diminuição de porcentagem de esmagamento nos meses do outono e do inverno, o período de maior permanência dos leitões no escamoteador, devido à menor temperatura ambiental, o que diminuiria as chances de morte por esmagamento.

Diferente do estado de São Paulo, no estado de Mato Grosso, nos meses de outono e de inverno, as baixas temperaturas ambiente ocorrem em poucos dias durante o inverno e com intensidade bem inferior as ocorridas no estado de São Paulo, o que, aliado a uma melhor regulagem do escamoteador, deve ter contribuído para não expressar sazonalidade para mortes por esmagamento. Outra observação que pode ser considerada é que os meses de frio, somados com o manejo inadequado de cortinas e temperatura do escamoteador, levam os leitões a deitarem bem próximos às matrizes, o que predispõe ao esmagamento. Os dados sobre a sazonalidade das mortes por esmagamento e diarreia estão apresentados nas Tabelas 2 e 3.

Tabela 2: Sazonalidade de morte por esmagamento e diarreia em granja no médio-norte de Mato Grosso

\begin{tabular}{lcc}
\hline \multirow{2}{*}{ Estação do ano } & \multicolumn{2}{c}{ Morte (\%) } \\
\cline { 2 - 3 } & Esmagamento & Diarreia \\
\hline Verão & 3,38 & 0,68 \\
Outono & 3,56 & 0,77 \\
Inverno & 3,02 & 0,60 \\
Primavera & 3,00 & 1,13 \\
\hline
\end{tabular}

Tabela 3: Causas de morte de leitões e intervalo de confiança para a média populacional

\begin{tabular}{l|c}
\hline Causas de mortes & Intervalo de confiança* \\
\hline Baixo peso & $1,06 \pm 0,14$ \\
Defeitos genéticos & $0,31 \pm 0,07$ \\
Diarreia & $0,80 \pm 0,20$ \\
Esmagamento & $3,24 \pm 0,19$ \\
Outras causas & $2,03 \pm 0,19$ \\
\hline
\end{tabular}

*Teste $t$ de Student $(P<0,05)$

\section{Conclusões}

Medidas específicas de controle das causas de mortalidades devem ser adotadas a fim de se evitar perdas, baseando-se no nível de tecnologia existente em cada SISCO. Como a morte por esmagamento, na primeira semana, é o principal fator de perdas de suínos nascidos vivos, medidas devem 
ser adotadas para melhorar as instalações de maternidade. Além disso, é importante realizar pesquisas para verificar

\section{Referências}

ABRAHÃO, A. A. F.; VIANA, W. L.; CARVALHO, L. F. O. S.; MORETTI, A. S. Causas de mortalidade de leitões neonatos em sistema intensivo de produção de suínos. Brazilian Journal of Veterinary Research and Animal Science, n. 41, p. 86-91, 2004.

CUTTLER, R. S. Preweaning mortality. In: STRAW, B. E.; D'ALLAIRE, S.; MENGELING, .L.;TAYLOR, D. J. Diseases of swing. 8. ed. Oxford: Blackwell Science, 1999, p. 985-1001.

FREITAS, H. T. Manejo para desmame de leitões aos 21 dias de idade. 1996. 43 p. Dissertação (Mestrado em Zootecnia) - Universidade Federal de Viçosa, Viçosa, 1996

LISBOA, M. N. T. S. Patologia e controle de natimortos. Suinocultura Industrial, v. 10, n. 125, p. 18-24, 1996. as causas de morte por esmagamento, em diferentes épocas do ano e em diferentes manejos.

MORES, N.; SOBESTIANSKY, J.; CIACCI, J. R.; AMARAL, A. L.; BARIONE, J. W. Fatores de risco na maternidade associados a diarreia, mortalidade e baixo desempenho de leitões. Comunicado Técnico, n. 178. Concórdia: Embrapa-CNPSA, 1991, 4 p.

MORES, N. Fatores que limitam a produção de leitões na maternidade. Periódico Técnico - Informativo, n. 09. Concórdia: Embrapa-CNPSA, 1993, $6 \mathrm{p}$.

SESTI, L. A. C.; SOBESTIANSKY, J. Aspecto da Produtividade. In: SOBESTIANSKY, J.; WENTZ, I.; SILVEIRA, P. R. S.; SESTI, L. A. C. Suinocultura intensiva: produção, manejo e saúde do rebanho. Concórdia: Embrapa-CNPSA, 1998. p. 29-43.

VRBANAC, I. et al. Preweaning losses of piglets on a state farm in Bosnia and Herzegovina. Preventive Veterinary Medicine, v. 24, p. 23-30, 1995. 